\title{
Influence of Loading Frequency on the Room-Temperature Fatigue of a Carbon-Fiber/SiC-Matrix Composite
}

\author{
Stephen F. Shuler, John W. Holmes, ${ }^{*}$ and Xin $\mathrm{Wu}^{\star}$ \\ Ceramic Composites Research Laboratory, Department of Mechanical Engineering and Applied Mechanics,
} The University of Michigan, Ann Arbor, Michigan 48109-2125

David Roach* Advanced Composites Division, E. I. du Pont de Nemours, Wilmington, Delaware 19880-0302

The influence of cyclic loading frequency on the tensile fatigue life of a woven-carbon-fiber/SiC-matrix composite was examined at room temperature. Tension-tension fatigue experiments were conducted under load control, at sinusoidal frequencies of 1,10 , and $50 \mathrm{~Hz}$. Using a stress ratio $\left(\sigma_{\min } / \sigma_{\max }\right)$ of 0.1 , specimens were subjected to maximum fatigue stresses of 310 to $405 \mathrm{MPa}$. There were two key findings: (1) the fatigue life and extent of modulus decay were influenced by loading frequency and (2) the postfatigue monotonic tensile strength increased after fatigue loading. For loading frequencies of 1 and $10 \mathrm{~Hz}$, the fatigue limit (defined at $1 \times 10^{6}$ cycles) was approximately 335 $\mathrm{MPa}$, which is over $80 \%$ of the initial monotonic strength of the composite; at $50 \mathrm{~Hz}$, the fatigue limit was below 310 MPa. During 1- and 10-Hz fatigue at a maximum stress of $335 \mathrm{MPa}$, the modulus exhibited an initially rapid decrease, followed by a partial recovery; at $50 \mathrm{~Hz}$, and the same stress limits, the modulus continually decayed. The residual strength of the composite increased by approximately $20 \%$ after $1 \times 10^{6}$ fatigue cycles at 1 or $10 \mathrm{~Hz}$ under a peak stress of $335 \mathrm{MPa}$. The increase in strength is attributed in part to a decrease in the stress concentrations present near the crossover points of the $0^{\circ}$ and $90^{\circ}$ fiber bundles.

\section{Introduction}

$\mathbf{F}$ IBER-REINFORCED ceramic-matrix composites are under development for use in advanced gas turbines, as structural members in aircraft, and as heat exchangers. Cyclic loading typically decreases the time-to-failure of continuous-fiber-reinforced ceramics, at both ambient ${ }^{1-7}$ and elevated ${ }^{2.8-10}$ temperatures. The fatigue experiments conducted to date with these composites have typically been performed at loading frequencies of $10 \mathrm{~Hz}$ and lower. Recent fatigue studies, conducted at loading frequencies above $10 \mathrm{~Hz}$, have shown that the tensiontension fatigue life of fiber-reinforced ceramics decreases as the fatigue loading frequency is increased." This finding is of practical interest since many components such as structural members in aircraft and gas turbine components can be subjected to a spectrum of loading frequencies, ranging from a few hertz to several thousand hertz. The frequency dependence of fatigue life has been attributed, in part, to the accelerated rate of microstructural damage caused by internal heating that occurs during the fatigue loading of ceramic-matrix composites. ${ }^{11-13}$ The

A. Evans-contributing editor

Manuscript No. 195597. Received June 15, 1992; approved May 17, 1993.

Presented at the 15th Annual Conference on Ceramics and Composites, Cocoa Beach, FL, January 1991.

"Member, American Ceramic Society. mechanism responsible for frictional (internal) heating involves the cyclic slip of fibers along debonded fiber-matrix interfaces. For woven composites, slip along fiber-fiber interfaces can also contribute to frictional heating.

$\mathrm{C}$-fiber/SiC-matrix $\left(\mathrm{C}_{\mathrm{f}} / \mathrm{SiC}\right)$ composites $^{14,15}$ are under consideration for use in applications requiring a low-density, hightoughness structural material; with surface coatings to prevent oxidation of the $\mathrm{C}$ fibers, elevated temperature use is possible. These composites are processed by chemical vapor infiltration of $\mathrm{SiC}$ into woven-fiber cloth (typically a $2 \mathrm{D}$ weave of $\mathrm{T}-300$ carbon fibers). Because of the large thermal expansion mismatch that exists between the fibers and the matrix, $\mathrm{C}_{\mathrm{f}} / \mathrm{SiC}$ composites may contain extensive processing-related matrix microcracking. This initial microcracking and associated interfacial debonding makes these composites susceptible to internal heating during fatigue loading. The amount of heating can be significant. For example, in earlier room-temperature fatigue studies with $0^{\circ} / 90^{\circ} \mathrm{C}_{\mathrm{f}} / \mathrm{SiC}$ composites, the surface temperature of fatigue specimens increased by approximately $4^{\circ} \mathrm{C}$ at a sinusoidal loading frequency of $10 \mathrm{~Hz}$, and by $32^{\circ} \mathrm{C}$ at 85 $\mathrm{Hz}$ (for stress limits of 250 and $10 \mathrm{MPa}$ ). ${ }^{13}$ Since the local temperature along the various interfaces in a composite will be much higher, the extent of microstructural damage and, hence, fatigue life, could be influenced by loading frequency.

To our knowledge, the fatigue behavior of initially microcracked fiber-reinforced ceramics has not been studied (earlier work by Holmes and Shuler ${ }^{13}$ on $\mathrm{C}_{\mathrm{f}} / \mathrm{SiC}$ composites addressed frictional heating only). The present study addresses the fatigue behavior of $\mathrm{C}_{\mathrm{f}} / \mathrm{SiC}$ composites at ambient temperature. Answers to the following questions are sought (in a general sense these questions also pertain to the fatigue of other initially microcracked composites):

(1) Is there a frequency dependence of fatigue life and microstructural damage accumulation?

(2) Is the initial matrix microcracking stable, and how does the microcrack density change with maximum fatigue stress?

(3) Does the presence of initial microcracking in a brittlematrix composite necessarily imply poor fatigue life?

(4) How is the residual strength of the composite affected by fatigue loading?

\section{Experimental Procedure}

\section{(1) Material and Specimen Geometry}

The composites used in this investigation were processed by chemical vapor infiltration (CVI) of SiC into woven $0^{\circ} / 90^{\circ} \mathrm{car}$ bon-fiber preforms. Preforms were made from T-300 carbonfiber cloth, with 1000 fibers per strand. The composites, processed as $200 \mathrm{~mm} \times 200 \mathrm{~mm}$ panels, had a [0/90] $]_{13 \mathrm{~s}}$ fiber layup (26 total plies, each with a single $0^{\circ} / 90^{\circ}$ cloth) and a nominal fiber content of $45 \mathrm{vol} \%$. As is typical of multiple-ply composites, not all plies were perfectly aligned in the panels; sectioning 
remnants from the panels showed that several of the plies were typically off axis-by as much as $8^{\circ}$. The bulk density of the infiltrated panels ranged from 1.93 to $1.98 \mathrm{~g} / \mathrm{cm}^{3}$. This compares with a theoretical density for this system of $2.54 \mathrm{~g} / \mathrm{cm}^{3}$, giving a porosity content of approximately $22 \%$.

Edge-loaded tensile specimens (Fig. 1(a)) were machined from the panels using diamond tooling. The microstructure of the panels is shown in Fig. 1(b). As mentioned in the introduction, thermal expansion mismatch between the fibers and matrix causes extensive processing-related matrix microcracking in $\mathrm{CVI} \mathrm{C}_{f} / \mathrm{SiC}$ composites. These cracks had an average spacing of $20 \mu \mathrm{m}$ along the minor faces (edges) of virgin specimens. The specimens had a gage length of $33 \mathrm{~mm}$ and a gage-section volume of approximately $624 \mathrm{~mm}^{3}$. To allow surface replicas of matrix cracking to be obtained, ${ }^{\dagger}$ the specimen edges (minor faces) were polished using $\mathrm{SiC}$ paper and diamond paste to a final finish of $1 \mu \mathrm{m}$. The polishing was performed by hand using a 10 -mm-diameter mandrel that was wrapped with $\mathrm{SiC}$ paper or diamond-impregnated nylon cloth and rotated at 100 $\mathrm{rpm}$. The polishing procedure can be summarized as follows: (1) 600 -grit $\mathrm{SiC}$ for $10 \mathrm{~min}$, (2) $45-\mu \mathrm{m}$ diamond paste for 10 min (mylon cloth), (3) 6- $\mu \mathrm{m}$ diamond paste for 10 min (nylon cloth) and, (4) $1.0-\mu \mathrm{m}$ diamond paste for $10 \mathrm{~min}$ (nylon cloth).

\section{(2) Test Procedure}

Monotonic tension and tension-tension fatigue tests were conducted at room temperature on a servohydraulic load-frame ${ }^{\ddagger}$ that was equipped with edge-loaded grips. ${ }^{16} \mathrm{~A}$ clip-on extensometer with a gage length of $33 \mathrm{~mm}$ was used to determine gage-section strains. ${ }^{\S}$ To prevent slippage, the extensometer knife edges were bonded to the specimen using a cyanoacrylate adhesive ("Superglue"). The ambient temperature was $22 \pm$ $0.2^{\circ} \mathrm{C}$ and the relative humidity ranged from $55 \%$ to $65 \%$. To prevent heat flow from the grips to the specimen, water cooling was used to maintain the temperature of the grips at $22^{\circ} \mathrm{C}$ (note that one of the grips was mounted on a hydraulic actuator which would cause heat flow to the specimen if grip cooling was not employed).

The room-temperature monotonic tensile behavior of fiberreinforced ceramics and glasses can be strongly influenced by loading rate. This loading rate dependence, first observed in Nicalon/CAS ${ }^{17}$ and Nicalon/ $\mathrm{SiC}^{18}$ composites, is caused by time-dependent phenomena such as subcritical crack growth, interfacial debonding, and the relief of residual stresses. Pernot and Zawada ${ }^{19}$ recently observed a similar rate dependence of monotonic tensile behavior for Nicalon/1723 glass composites that were loaded monotonically to failure under load control or displacement control. Based upon results from these previous studies, monotonic tensile testing of the $\mathrm{C}_{\mathrm{f}} / \mathrm{SiC}$ composite was conducted at a loading rate of $50 \mathrm{MPa} / \mathrm{s}$.

Fatigue testing was performed under load control at sinusoidal loading frequencies of 1,10 , and $50 \mathrm{~Hz}$. All fatigue experiments were performed using a stress ratio $\left(\sigma_{\min } / \sigma_{\max }\right)$ of 0.1 . For loading frequencies of 1 and $10 \mathrm{~Hz}$, specimens were subjected to maximum fatigue stresses of 335 to $405 \mathrm{MPa}$; at $50 \mathrm{~Hz}$, maximum stresses of 310 to $385 \mathrm{MPa}$ were studied. Specimens were loaded to the maximum fatigue stress at a rate of $100 \mathrm{MPa} / \mathrm{s}$,

${ }^{\dagger}$ Acetyl cellulose film, $0.08 \mathrm{~mm}$ thick. Energy Beam Sciences, Inc., Agawam, MA.

'Load frame Model No. 810, Material Test Systems (MTS), Minneapolis, MN.

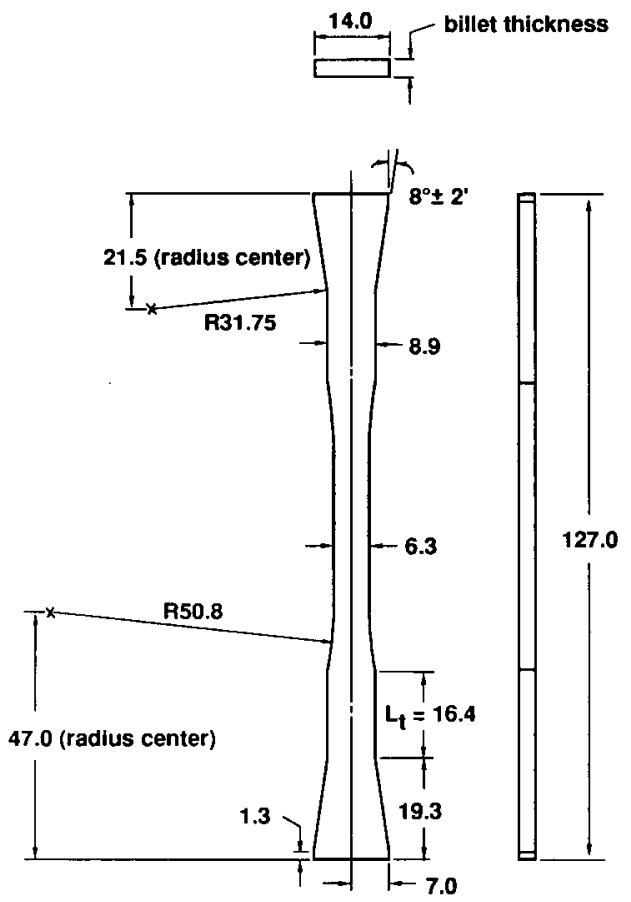

(a)

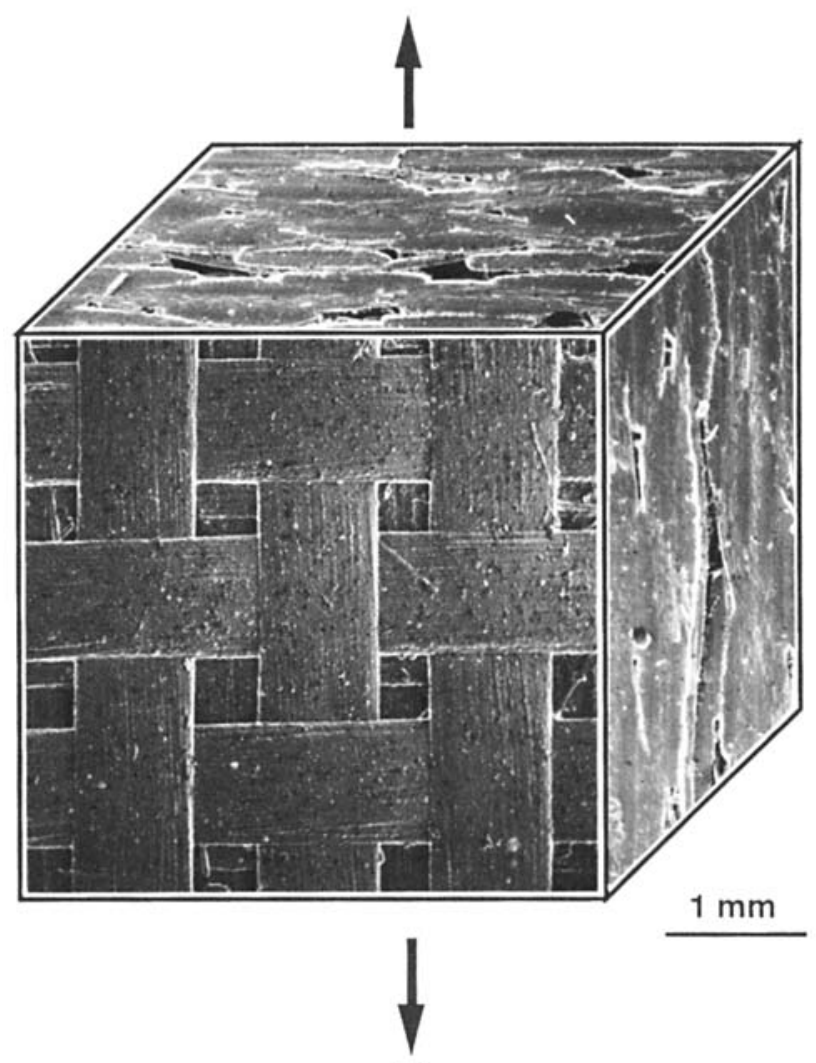

(b)

Fig. 1. (a) Edge-loaded tensile specimen used to investigate the monotonic tension and tensile fatigue behavior of $\mathrm{C}_{\mathrm{f}} / \mathrm{SiC}$ composites. Although this geometry proved satisfactory (over $90 \%$ gage-section failures), less complicated edge-loaded specimen geometries with the same gage length have been found to perform equally well for the ambient and elevated-temperature monotonic tension and tension-tension fatigue testing of $\mathrm{C}_{\mathrm{f}} / \mathrm{SiC}$ composites. ${ }^{16}$ (b) SEM micrograph showing fiber architecture and porosity present in the gage section of a virgin specimen (the processing-related matrix microcracking is not observable at this magnification). 
followed immediately by cyclic loading at the desired frequency. Fatigue runout was arbitrarily set at $1 \times 10^{6}$ cycles, which corresponds to $277.8 \mathrm{~h}$ of testing at $1 \mathrm{~Hz}, 27.8 \mathrm{~h}$ at $10 \mathrm{~Hz}$, and $5.6 \mathrm{~h}$ at $50 \mathrm{~Hz}$. Acetate-film replicas of the specimen edges were taken at periodic intervals to quantify the change in matrix crack density that occurred during fatigue. In all instances, replicas were obtained by stopping the fatigue test and maintaining a stress of $10 \mathrm{MPa}$ on the specimen while taking the replicas. Although crack definition could be slightly improved by maintaining a higher stress on the specimen while taking replicas, preliminary trials had shown that substantially higher stresses (e.g., 50 to $100 \mathrm{MPa}$ ) caused crack growth during the roughly 3 to $5 \mathrm{~min}$ required to obtain a replica (this was particularly evident during the initial stages of fatigue, where the crack spacing had not yet reached a saturation level characteristic of the particular fatigue stress). The values for crack spacing reported in this paper represent the mean value obtained by measuring the distances between at least 200 crack pairs.

As noted in the Introduction, fiber-reinforced ceramics can undergo significant internal heating during fatigue loading. Since internal heating could exacerbate the accumulation of microstructural damage, the temperature rise of the specimens was recorded during the fatigue experiments. An infrared pyrometer, focused at the center of the specimen gage section, was used for the temperature measurements. Data from the pyrometer were stored at $1-\mathrm{s}$ intervals throughout the fatigue experiments. Further details concerning the equipment and experimental approach used for similar fatigue and frictional heating experiments can be found in Ref. 7 .

\section{Results and Discussion}

\section{(1) Monotonic Tensile Behavior}

At room temperature, the woven $\mathrm{C}_{f} / \mathrm{SiC}$ composite exhibits nonlinear stress-strain behavior from the onset of loading (see Fig. 2). Extension of the processing-related matrix microcracking and accompanying interfacial debonding, along with the progressive fracture of fibers at higher stresses, are responsible for the nonlinear behavior and decrease in modulus observed during monotonic loading. Based upon the results obtained from three experiments, the ultimate strength of the composite ranged from 415 to $425 \mathrm{MPa}$ and the failure strain ranged from approximately 0.8 to $0.9 \%$. These data are consistent with values obtained by others for $0^{\circ} / 90^{\circ} \mathrm{C}_{\mathrm{f}} / \mathrm{SiC}$ composites with similar fiber fractions and densities. ${ }^{20}$

\footnotetext{
'Model No. 5402, Everest Interscience, Fullenton, CA.
}

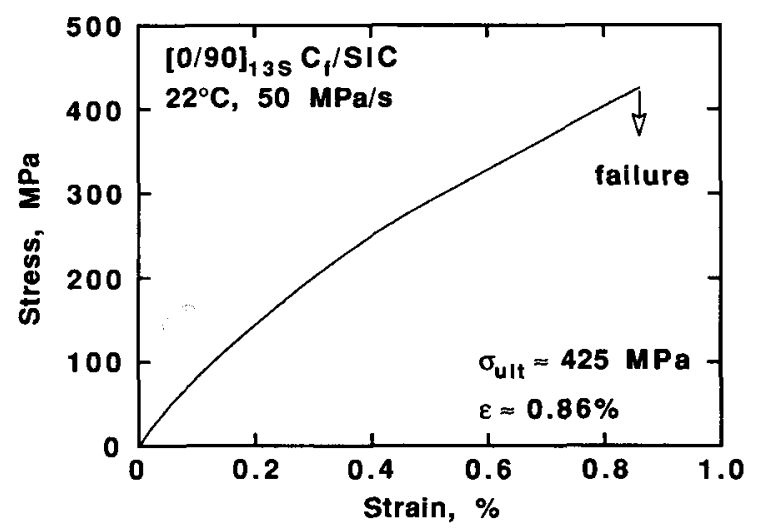

Fig. 2. Typical room-temperature monotonic tensile behavior of $[0 / 90]_{13 \mathrm{~S}} \mathrm{C}_{\mathrm{f}} / \mathrm{SiC}$ at a loading rate of $50 \mathrm{MPa} / \mathrm{s}$.

\section{(2) Fatigue Life-SN Curves}

The room-temperature fatigue life of the $\mathrm{C}_{\mathrm{f}} / \mathrm{SiC}$ composite is shown in Fig. 3 as a function of maximum fatigue stress and loading frequency. Above $335 \mathrm{MPa}$, progressive fatigue failures were observed at all loading frequencies. Considering the wide scatter in the fatigue data, there was no apparent difference in the fatigue life at 1 and $10 \mathrm{~Hz}$. The fatigue life at $50 \mathrm{~Hz}$ was, however, consistently lower for all stress levels. At loading frequencies of 1 and $10 \mathrm{~Hz}$, fatigue runout $\left(1 \times 10^{6}\right.$ cycles $)$ was observed at a peak stress of $335 \mathrm{MPa}$; at $50 \mathrm{~Hz}$ this stress caused failure in approximately $1 \times 10^{5}$ cycles. At $310 \mathrm{MPa}$, which was the lowest stress examined at $50 \mathrm{~Hz}$, failure occurred within 300000 cycles. For purposes of discussion, $335 \mathrm{MPa}$ will be defined as the fatigue limit for $1-$ and $10-\mathrm{Hz}$ fatigue. It should be noted that $335 \mathrm{MPa}$ is close to $80 \%$ of the average monotonic tensile strength found for virgin specimens. As a function of the ultimate strength, this number is quite impressive compared to other fiber-reinforced ceramics. ${ }^{1-6,11}$ Although the $50-\mathrm{Hz}$ fatigue limit is obviously lower than the fatigue limit at 1 and $10 \mathrm{~Hz}$, a lack of specimens precluded additional testing to more accurately define the $50-\mathrm{Hz}$ fatigue limit. Possible mechanisms for the reduction in fatigue life at $50 \mathrm{~Hz}$ are discussed in a later section.

Slow crack growth under static loading is known to occur in monolithic ceramics. ${ }^{21-25}$ To determine if failure of the $\mathrm{C}_{\mathrm{f}} / \mathrm{SiC}$ composites could be attributed to slow crack growth, rather than mechanical cycle-by-cycle fatigue damage, a specimen was loaded to a stress of $375 \mathrm{MPa}$ and held for $28 \mathrm{~h}(28 \mathrm{~h}$ roughly corresponds to the duration of a fatigue test conducted for $1 \times 10^{6}$ cycles at $10 \mathrm{~Hz}$ ). Under cyclic loading at a peak fatigue stress of $375 \mathrm{MPa}$, failure occurred in less than $4 \mathrm{~h}$ for all loading frequencies. The statically loaded specimen did not fail, even though the stress was significantly higher than the mean stress of $206 \mathrm{MPa}$ imposed on the fatigue specimens. Clearly, cyclic loading accelerates the damage process.

\section{(3) Microstructural Damage}

(A) Change in Matrix Crack Density: During fatigue loading the processing-related matrix cracks will extend and, in parallel, new cracks will form until a constant matrix crack density is established (a constant crack spacing will occur only if the fatigue stress is sufficiently low enough to avoid extensive fiber fracture and eventual composite failure). The equilibrium crack spacing is influenced by external variables such as maximum fatigue stress, stress range, and temperature. To determine how the density of matrix cracks was influenced by maximum fatigue stress, surface replicas were taken at periodic intervals during the 1 - and $10-\mathrm{Hz}$ fatigue tests. Measurements of crack

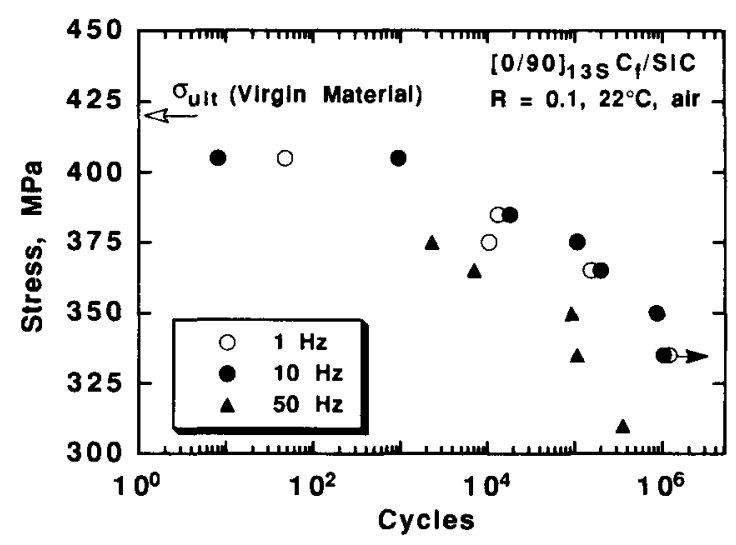

Fig. 3. $S-N$ curve showing the influence of peak fatigue stress and sinusoidal loading frequency on the room-temperature fatigue life of $0^{\circ} / 90^{\circ} \mathrm{C}_{\mathrm{f}} / \mathrm{SiC}$ composites. For loading frequencies of 1 and $10 \mathrm{~Hz}$, specimens survived $1 \times 10^{6}$ cycles at a maximum stress of $335 \mathrm{MPa}$ (duplicate experiments were conducted at this stress level). The fatigue life was consistently lower at $50 \mathrm{~Hz}$. 
spacing were not made during fatigue at $50 \mathrm{~Hz}$, since periodic interruption of the fatigue experiments to obtain replicas would interfere with the internal heating (discussed in Section III(6)), which could play a role in the development of microstructural damage. At 1 and $10 \mathrm{~Hz}$, where the temperature rise was much lower, the disruption of frictional heating by periodic unloading to obtain replicas would have a minimal impact on microstructural damage accumulation (note that the cyclic energy dissipation, and hence temperature rise during fatigue loading, is linearly proportional to the loading frequency ${ }^{7}$ - the temperature rise at $50 \mathrm{~Hz}$ is roughly 50 times greater than it is at $1 \mathrm{~Hz}$ ).

A representative micrograph showing the crack density after 1000 fatigue cycles at a loading frequency of $1 \mathrm{~Hz}$ and maximum stress of $335 \mathrm{MPa}$ is given in Fig. 4. The decrease in mean crack spacing that occurred during fatigue is plotted in Fig. 5 for a peak fatigue stress of $375 \mathrm{MPa}$ (the inset in Fig. 5 shows the change in crack spacing at $335 \mathrm{MPa}$ ). At $335 \mathrm{MPa}$ the surface crack spacing reached a constant level within the first 100 cycles. The crack spacing at 100 cycles was only $38 \%$ of the initial crack spacing (in other words, the surface density of matrix cracks was roughly 2.6 times greater than that measured after processing). At $375 \mathrm{MPa}$, a stress level which caused specimen failure, the crack spacing showed a similar rapid rate of decrease during the first 100 cycles, to $34 \%$ of the initial crack spacing; at this stress the crack spacing remained approximately constant between 100 and 5000 cycles, after which it decreased sharply prior to specimen failure. The initial decrease in crack spacing occurred uniformly throughout the gage section. The decrease that occurred beyond 5000 cycles was primarily caused by the formation of additional matrix cracks that were localized within several narrow bands (roughly $5 \mathrm{~mm}$ in length) which were randomly located along the gage section. As expected, the highest crack density was found near the final failure location of the specimen.

(B) SEM Examination of Specimens: The fatigue specimens were examined by optical and electron microscopy to gain insight into how microstructural damage evolves during fatigue loading. As a consequence of the woven 2-D fiber architecture, nonuniform stresses and strains develop in the axial, width, and thickness directions of the specimen. Because of the nonuniformity in stress and strain near the crossover points of the fiber bundles, there is extensive fracture and spallation of the $\mathrm{SiC}$ matrix at these locations (see Figs. 6(a) and (b)). In parallel with this damage mode, separation between the fibers and the infiltrated matrix occurs within the individual fiber bundles (see Fig. 6(c)). To accommodate the nonuniform strain developed between neighboring plies, delamination between individual plies will occur (Fig. 6(d)). Generally, for a given fatigue

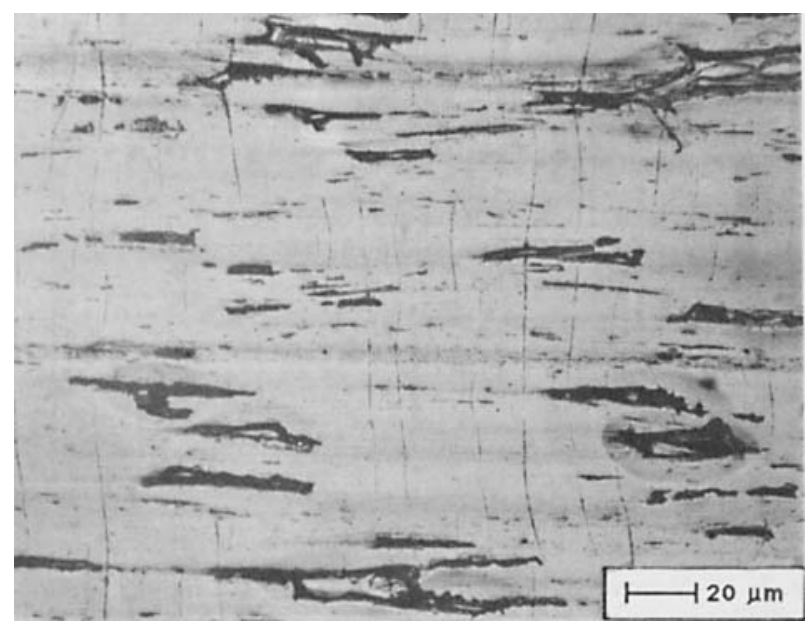

Fig. 4. Optical micrograph of an acetate-film replica showing matrix crack density after 1000 cycles at $1 \mathrm{~Hz}$ under a maximum fatigue stress of $335 \mathrm{MPa}$.

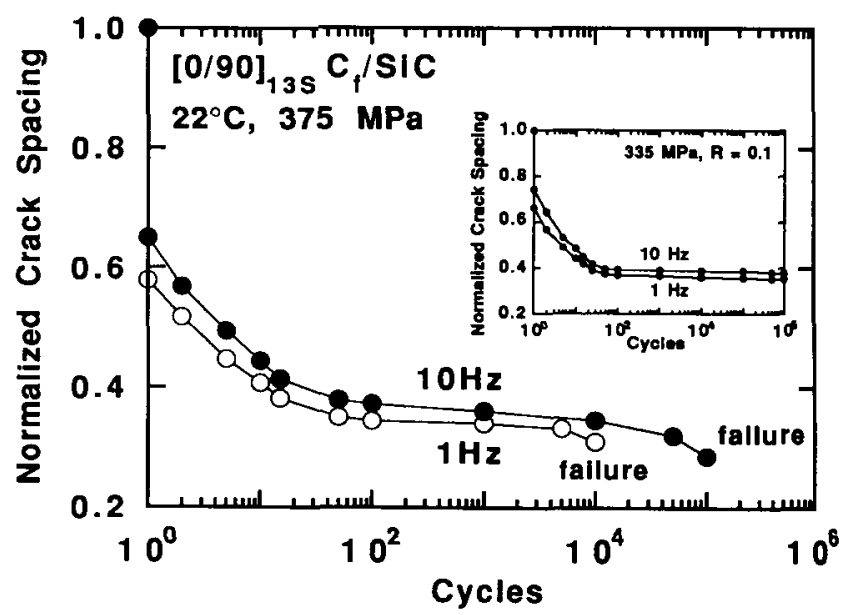

Fig. 5. Decrease in mean crack spacing observed during the fatigue of $\mathrm{C}_{\mathrm{f}} / \mathrm{SiC}$ at loading frequencies of 1 and $10 \mathrm{~Hz}$ for maximum fatigue stresses of 375 and $335 \mathrm{MPa}$ (inset).

stress, the amount of delamination between plies was considerably higher at $50 \mathrm{~Hz}$ compared to that observed at 1 or $10 \mathrm{~Hz}$. The fatigue process, as opposed to static loading, assists the damage process by allowing wear to occur between the various interfaces in the composite (as discussed later, at low fatigue stresses and loading frequencies, the "damage" process that occurs during fatigue loading can have a beneficial effect on the residual strength of the composite).

(C) Influence of Nonuniform Stresses on Microstructural Damage Modes: It is of interest to speculate on the mechanisms responsible for the microstructural damage modes shown in Figs. 6(a-d) above. As shown schematically in Figs. 7(a-d), nonuniform stress and strain distributions develop at different scales along three orthogonal directions. At the macroscopic scale, the 2-D fiber bundle configuration produces nonuniform stress distributions along the axial and width directions within individual plies; the random stacking of the plies produces a nonuniform stress distribution in the thickness direction of the specimen (Fig. 7(a)). Nonuniform stretching of plies produces a shear stress and contact pressure at the contact points between plies, resulting in delamination between the plies (Fig. 7(b)). Within individual fiber bundles, cracking of the matrix occurs as the $0^{\circ}$ bundles attempt to align with the tensile loading direction, and by bending of the $90^{\circ}$ bundles which tend to contract to accommodate movement of the $0^{\circ}$ bundles (Fig. 7(c)). On a finer scale, the straightening of individual $0^{\circ}$ fibers and simultaneous bending of the $90^{\circ}$ fibers produces matrix cracking between individual fibers and fiber-matrix debonding (Fig. $7(d))$. Figures $7(a-d)$ provide insight into the nonuniform stresses experienced by the microstructure during tensile loading (monotonic or fatigue). In parallel with the damage caused by nonuniform stresses, there is a progressive wear of interfaces that occurs during cyclic loading (see later discussion). More detailed mechanics analysis of the microstructural damage evolution during fatigue loading is currently under way and will be described in detail in a future paper.

\section{(4) Cyclic Stress-Strain Response}

Typical cyclic stress-strain curves from the fatigue experiments conducted at $10 \mathrm{~Hz}$ are shown in Figs. 8(a) and (b) for maximum stresses of 335 and $375 \mathrm{MPa}$. Compared to the tangent modulus measured at the end of the initial loading ramp, a considerable increase in average modulus occurred on the first fatigue cycle (this increase can be seen in Figs. 8(a) and (b) for stresses above approximately $150 \mathrm{MPa}$ ). Using the first-cycle modulus as a reference the modulus decreased most rapidly during the first 1000 fatigue cycles. As indicated by the strain ratchetting in Figs. 8(a) and (b), this modulus decay was accompanied by an increase in nonrecoverable strain. 

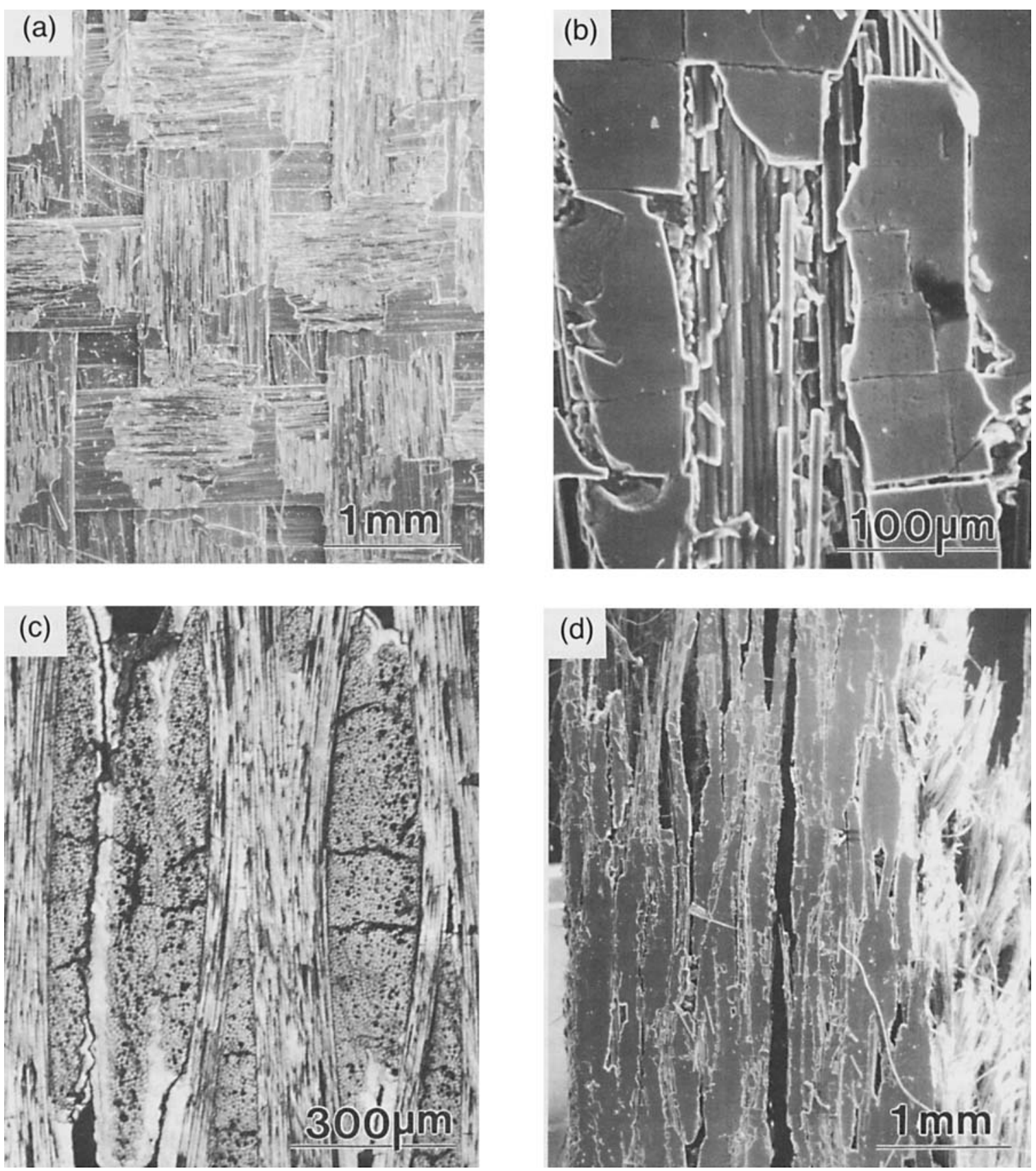

Fig. 6. Micrographs showing typical microstructural damage present after fatigue at a loading frequency of $10 \mathrm{~Hz}$ and peak stress of $375 \mathrm{MPa}$ (a) Damage present along the broad faces of the specimen gage section. Because of nonuniform stress and strain near the crossover points of the fiber bundles, the SiC matrix fractures and spalls at these locations. (b) Local enlargement of Fig. 6(a), showing SiC damage near the crossover points in the woven cloth. (c) Damage along minor face of specimen, showing cracking within the transverse fiber bundles. (d) Lower-magnification view of minor face showing delamination between plies near the final failure location.

Both the modulus decrease and the strain ratchetting indicate the progressive accumulation of microstructural damage. The increase in modulus found on the first loading cycle is attributed to the "straightening" of the $0^{\circ}$ fibers that occurs near the crossover points in the woven fiber cloth (the matrix fracture that occurs locally near the crossover points provides a mechanism for the extension and alignment of fiber bundles parallel to the tensile loading direction).

As expected, for a given loading frequency the extent of hysteresis and strain ratchetting increased as the peak fatigue stress was increased, indicating an increase in the amount of cyclic damage accumulation. ${ }^{* *}$ Compared to $1-\mathrm{Hz}$ fatigue, and for all stress levels, the hysteresis was larger at 10 and $50 \mathrm{~Hz}$. Similar hysteresis in the cyclic stress-strain response has been observed for other fiber-reinforced composites. ${ }^{1-11}$ Independent of loading frequency, the amount of hysteresis decreased with continued cycling, suggesting a wear process occurred along the various fiber/fiber and fiber/matrix interfaces within the composite.

\footnotetext{
**Note the decrease in hysteresis indicates a decrease in the energy dissipation per cycle. The energy dissipation can be readily calculated by multiplying the area
} enclosed by a hysteresis loop by the loading frequency. 


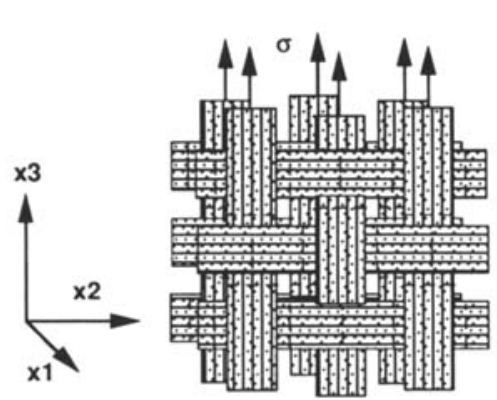

(a) Nonuniform macroscopic stress and strain distribution responsible for matrix and fiber damage

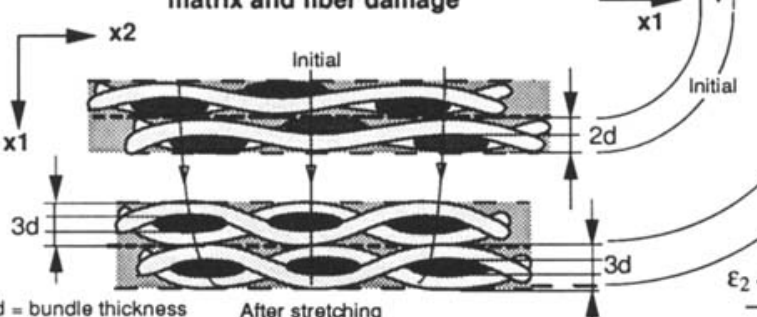

(b) Ply delamination caused by normal and shear

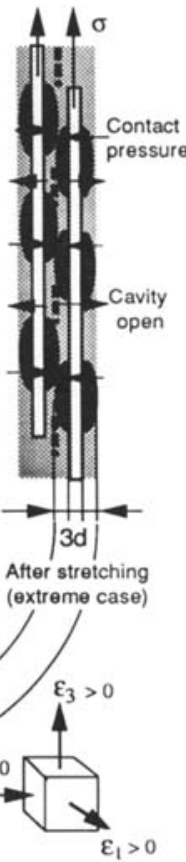
stresses of nonuniform stretching plies
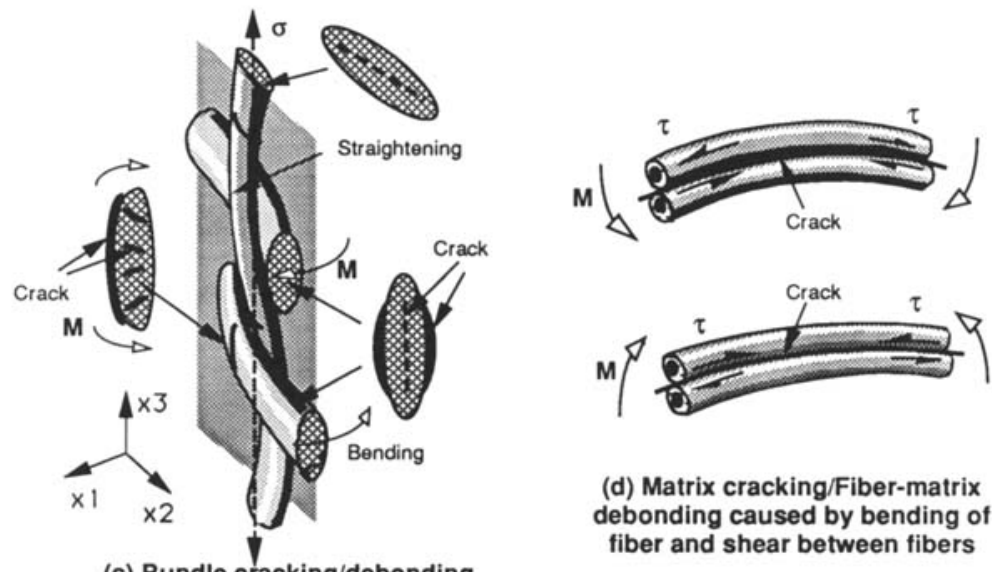

(c) Bundle cracking/debonding

bundles and bending of $90^{\circ}$ bundles

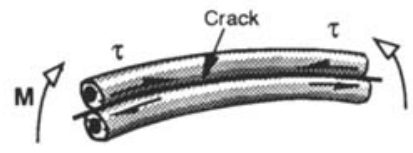

(d) Matrix cracking/Fiber-matrix debonding caused by bending of fiber and shear between fibers

Fig. 7. Schematic representations of microstructural fatigue damage observed on different planes within a fatigue specimen. The nonuniform stresses and strains that develop in woven composites subjected to far-field tensile loading are largely responsible for the microstructural damage. (a) Nonuniform stresses develop near the crossover points of strands within individual plies which leads to matrix fracture and spallation (see Figs. 6(a) and (b)). Because the plies are somewhat staggered in the thickness direction, nonuniform stresses also develop in this direction. (b) As the fiber bundles attempt to align parallel with the tensile loading direction, the local contact force that develops between the plies can initiate ply delamination (see Fig. 6(d)). (c) At a finer scale, matrix fracture within the fiber bundles (see Fig. 6 (c)) occurs as the $0^{\circ}$ fiber bundles attempt to align parallel with the tensile loading direction and simultaneously the $90^{\circ}$ bundles undergo bending. (d) On an even finer scale, cracking and separation between individual fibers occurs as the $0^{\circ}$ fibers align themselves with the tensile loading direction and the $90^{\circ}$ fibers undergo bending.

\section{(5) Change in Composite Modulus}

The influence of maximum fatigue stress and accumulated fatigue cycles on the composite modulus is shown in Figs. 9(a) and (b) for loading frequencies of 1 and $10 \mathrm{~Hz}$. The modulus exhibited a pronounced sensitivity to small changes in the maximum fatigue stress. For example, a continual decay in modulus was observed during fatigue at peak stresses of $350 \mathrm{MPa}$ and higher. In contrast, an initial decrease, followed by a plateau and partial recovery in modulus, was found for fatigue at a maximum stress of $335 \mathrm{MPa}$ (note that this is only $15 \mathrm{MPa}$ below the stress level that caused a progressive decrease in modulus and fatigue failure). A partial recovery in modulus has also been observed during the fatigue of other fiber-reinforced ceramic composites. ${ }^{57} \mathrm{~A}$ possible explanation for this increase in modulus is a partial recovery in interfacial (frictional) shear stress during long-duration cyclic loading. Although not determined for the $0^{\circ} / 90^{\circ}$ composites studied here, support for this mechanism comes from an earlier study ${ }^{7}$ that examined the change in interfacial frictional shear stress that occurred during the roomtemperature fatigue of unidirectional Nicalon/CAS-II composites. After an initially rapid decrease from 20 to $5 \mathrm{MPa}$, the frictional shear stress recovered to approximately $6 \mathrm{MPa}$. The initial decrease in frictional shear stress is caused by cyclic wear damage along the numerous fiber-matrix interfaces within the composite (in woven composites this would include wear along the interfaces between fiber bundles); a partial recovery could occur by the accumulation of debris along the fiber/ matrix interface or interaction with humidity in the test environment. Since several of the plies in the $\mathrm{C}_{\mathrm{f}} / \mathrm{SiC}$ composites were off axis by as much as $8^{\circ}$, it is also possible that geometric stiffening could have contributed to the recovery in modulus. Geometric stiffening, which would occur through a process 


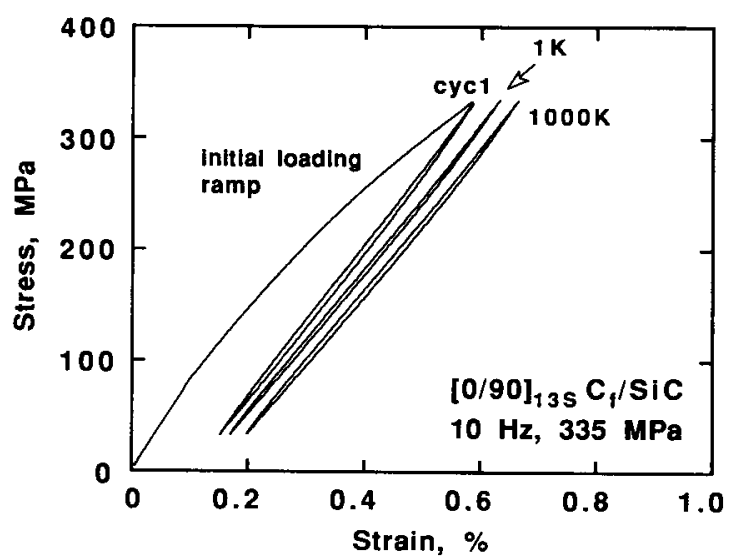

(a)

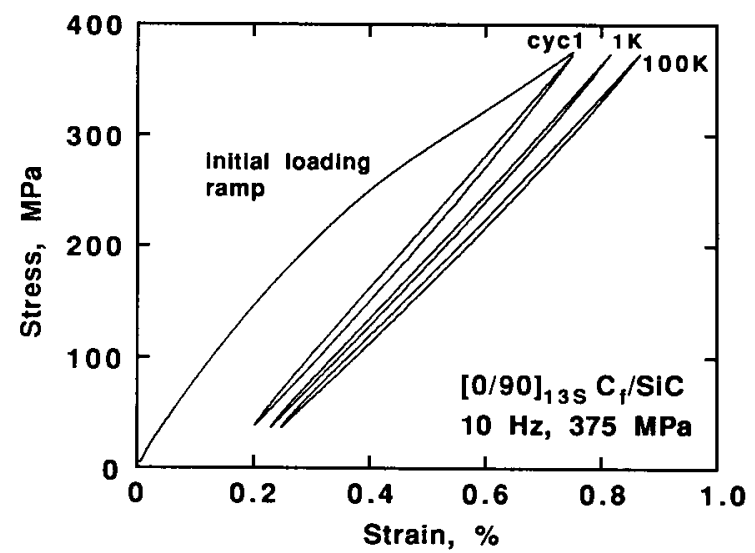

(b)

Fig. 8. Cyclic stress-strain behavior of $\mathrm{C}_{\mathrm{f}} / \mathrm{SiC}$ composites fatigued at a loading frequency of $10 \mathrm{~Hz}$ : (a) $335 \mathrm{MPa}$ peak stress; the test was stopped at $1 \times 10^{6}$ cycles. (b) $375 \mathrm{MPa}$ peak stress; failure occurred at 10300 cycles.

involving matrix microcracking and partial delamination between plies, would allow fiber bundles which are initially off axis to achieve an orientation closer to the tensile loading axis. A third mechanism, which would be unique to composites containing woven fiber cloth, would involve extension of the fibers near the kinks where fiber bundles cross over one another. For brittle-matrix composites at room temperature, this mechanism would require that the matrix surrounding the crossover points be degraded by cyclic loading; this would permit the movement or sliding of the fiber bundles in a direction parallel to the loading axis (as shown in Fig. 7, a mechanism for this degradation would involve fiber debonding and matrix fracture caused by stress concentrations at the kinks, followed by cyclic wear and abrasion of the fibers and matrix near the crossover points).

A comparison of the cyclic change in modulus that occurred during fatigue at 1,10 , and $50 \mathrm{~Hz}$ is shown in Fig. 10 for maximum fatigue stresses of 335 and $375 \mathrm{MPa}$. Beyond 1000 fatigue cycles, the decrease in modulus at $50 \mathrm{~Hz}$ was considerably greater than at 1 and $10 \mathrm{~Hz}$, indicating an increase in the rate at which microstructural damage accumulates (this result is consistent with the decreased fatigue life at $50 \mathrm{~Hz}$ ).

As discussed in detail above, during fatigue at $335 \mathrm{MPa}$ the modulus initially decreases, reaches a minimum, and finally undergoes a partial recovery. To determine if the observed increase in matrix crack density was responsible for the initial decrease in modulus, it is instructive to compare the cyclic rate of modulus decay with the rate of decrease in matrix crack spacing. These comparisons are shown in Fig. 11 for loading frequencies of 1 and $10 \mathrm{~Hz}$. Although the surface crack spacing reached a plateau within 100 cycles, the modulus continued to decrease until roughly 100000 cycles. This pronounced lag in stabilization of the modulus, which has also been observed for unidirectional Nicalon/CAS composites, ${ }^{7}$ indicates that additional mechanisms contribute to the initial decay in modulus. Possible mechanisms that could influence the decrease in modulus include (1) additional crack growth in the interior of the specimen, (2) progressive interfacial debonding, (3) a decrease in interfacial shear stress caused by wear along fiber/fiber and fiber/matrix interfaces, and (4) the progressive fracture of fibers that have strengths at the low end of the statistical strength distribution. This latter mechanism would act in parallel with interfacial debonding and frictional wear, both of which would cause a progressive transfer of load from the matrix to the fibers as the frictional shear stress along the interfaces decreases (it is important to note that as additional load is transferred to the fibers, the probability of fiber failure increases).

\section{(6) Frictional Heating during Fatigue}

The temperature rise measured during $10-\mathrm{Hz}$ fatigue at a peak stress of $335 \mathrm{MPa}$ is shown in Fig. 12. For fatigue at stress levels that were low enough to avoid fatigue failure, earlier studies with $\mathrm{C}_{\mathrm{f}} / \mathrm{SiC}^{13}$ and Nicalon $\mathrm{SiC}_{\mathrm{f}} / \mathrm{CAS}-\mathrm{II}^{7.11}$ composites had shown that the temperature rise associated with frictional heating typically exhibits an initially sharp increase, followed by a peak and gradual decay. Although frictional heating requires the presence of interfacial debonding, it does not require that fractured fibers be present, since relative slip can

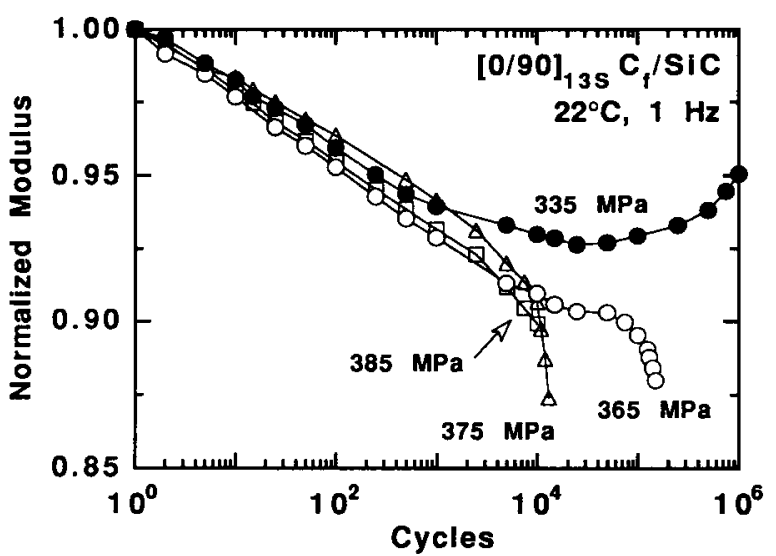

(a)

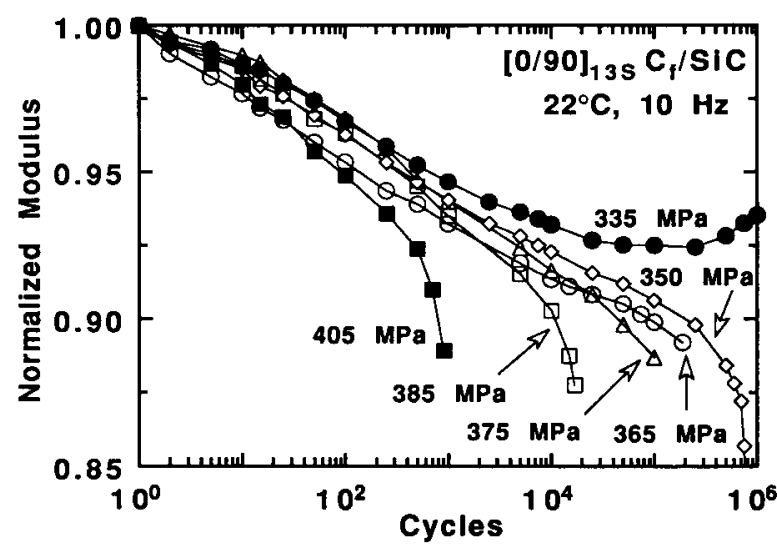

(b)

Fig. 9. Influence of maximum fatigue stress and accumulated fatigue cycles on the cyclic stress-strain modulus of $\mathrm{C}_{\mathrm{f}} / \mathrm{SiC}$ composites fatigued at loading frequencies of 1 and $10 \mathrm{~Hz}$. The modulus, determined by a best fit through the upper and lower limits of the cyclic stress-strain curves (see Figs. 8(a) and (b)) was normalized with respect to the average modulus for the first fatigue cycle. 


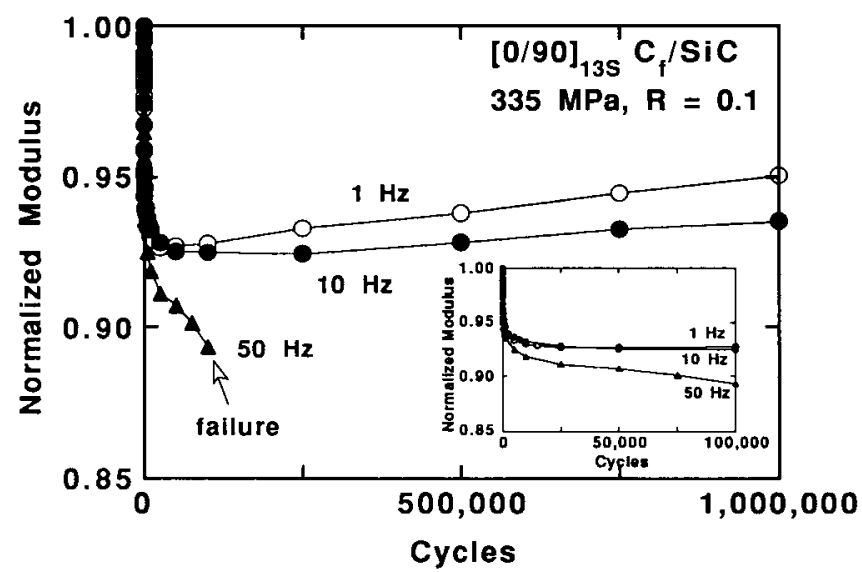

(a)

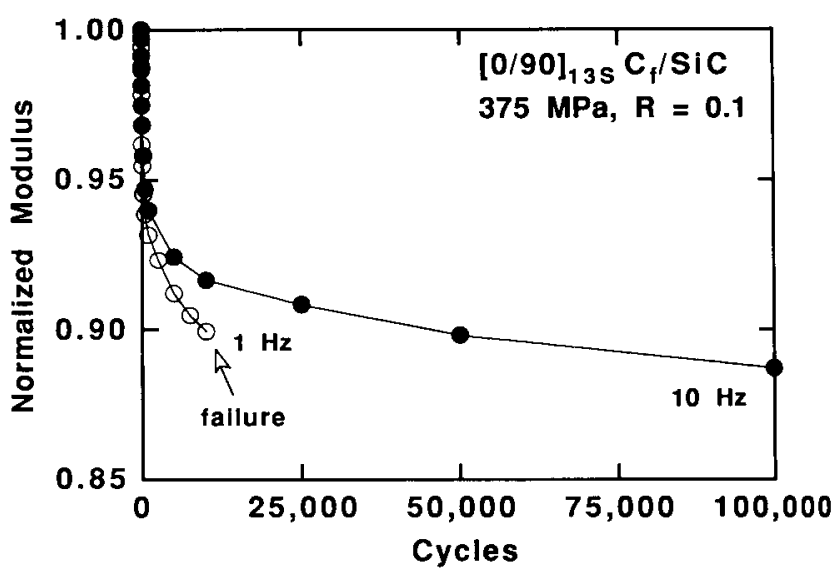

(b)

Fig. 10. Influence of loading frequency and accumulated fatigue cycles on the cyclic stress-strain modulus of $\mathrm{C}_{\mathrm{f}} / \mathrm{SiC}$ composites: (a) $335 \mathrm{MPa}$ (the inset shows initial decrease up to 100000 cycles); note the partial recovery in modulus at 1 and $10 \mathrm{~Hz}$ and the progressive decay at $50 \mathrm{~Hz}$. (b) 375 $\mathrm{MPa}$. The modulus was normalized with respect to the average modulus measured for the first fatigue cycle.

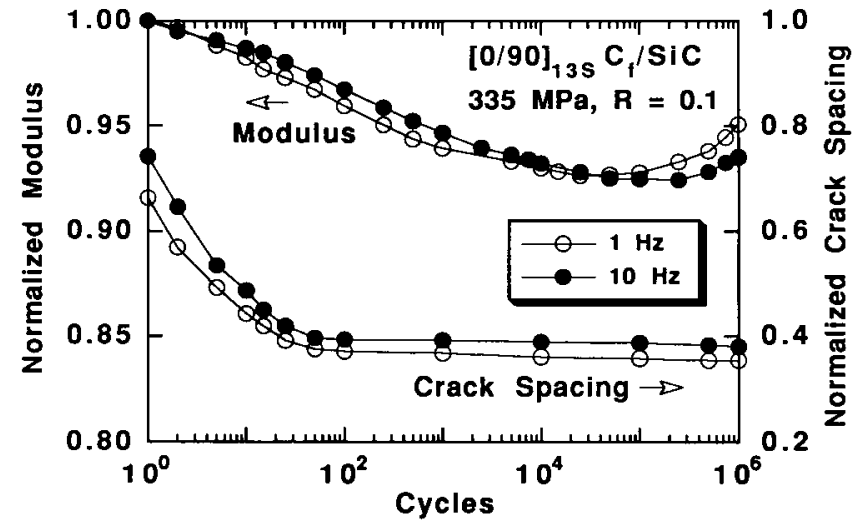

Fig. 11. Comparison between the cyclic rate of modulus decay during the initial stages of fatigue and the rate of decrease in matrix crack spacing for $1-$ and $10-\mathrm{Hz}$ fatigue loading at $335 \mathrm{MPa}$.

occur along debonded fiber/matrix interfaces and between fiber bundles and the surrounding matrix; in fact, for low stress levels, where the percentage of fractured fibers is small, the majority of heating is caused by slip of unfractured fibers. In general terms, the initial increase in temperature rise is caused by the progressive accumulation of microstructural damage, which involves an increase in matrix crack density and debonding between fiber bundles and between individual fibers and the surrounding matrix; if the applied stress is sufficient to cause fiber fracture, the slip of fractured fibers will also contribute to the temperature rise.

Since the temperature rise is related to the microstructural damage state of the composite, it is interesting to compare the temperature change that occurs during fatigue with the cyclic change in modulus. This comparison is shown in Fig. 12 for fatigue at $10 \mathrm{~Hz}$ under a peak stress of $335 \mathrm{MPa}$. The specimen temperature increased during the first 25000 cycles to a maximum of roughly $12^{\circ} \mathrm{C}$, and remained approximately constant up to 50000 cycles, after which it slowly decayed to approximately $8.5^{\circ} \mathrm{C}$ at $1 \times 10^{6}$ cycles. The initial decrease in modulus roughly parallels the increase in specimen temperature; however, the temperature rise peaks at roughly 25000 cycles, whereas the modulus reaches a minimum between 100000 and 200000 cycles. The initial increase in temperature is attributed to the increase in matrix crack density as well as an increase in the number and length of debonded fiber/matrix interfaces in

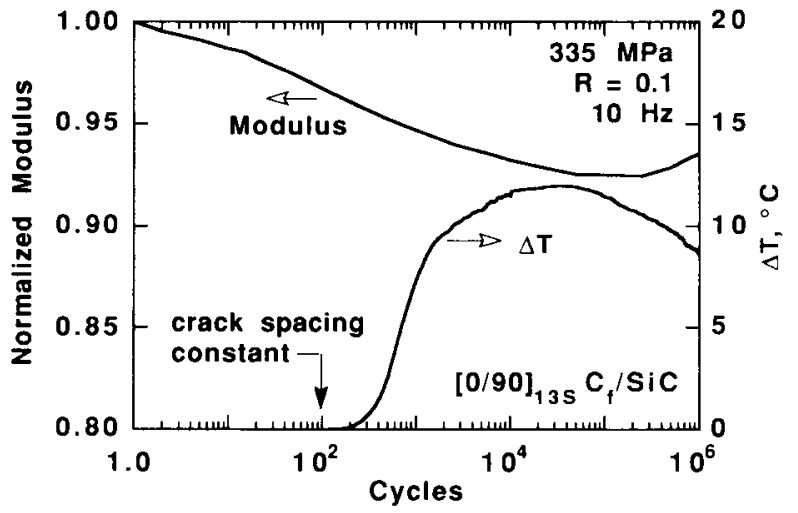

Fig. 12. Temperature rise and change in modulus during the fatigue of $\mathrm{C}_{f} / \mathrm{SiC}$ at $10 \mathrm{~Hz}$ and a maximum stress of $335 \mathrm{MPa}$. After an initial increase, caused by an increase in matrix crack density and interfacial debonding, the temperature slowly decays. This decay is attributed to wear along the various fiber/matrix interfaces within the composite.

the composite (note that although the surface crack density rapidly stabilizes, further crack growth is possible in the interior of the composite). The initial decay in temperature is attributed to additional wear damage along the fiber/matrix interfaces. At a later stage, the slight recovery in modulus, which as noted earlier has been observed for other fiber-reinforced ceramics, may be caused by fretting damage along the fiber/matrix interface, which would increase the average level of frictional shear stress (note that for load-controlled fatigue, an increase in specimen stiffness will lead to a proportional decrease in strain amplitude $^{\dagger \dagger}$ ). Since frictional heating roughly scales with the strain range, an increase in modulus will cause a proportional decrease in temperature.

The maximum temperature rise is plotted in Fig. 13 for the fatigue experiments performed at 1 and $10 \mathrm{~Hz}$, and also for several of the experiments conducted at $50 \mathrm{~Hz}$. Consistent with previous work on $\mathrm{C}_{\mathrm{f}} / \mathrm{SiC}$ composites, ${ }^{13}$ the temperature rise increased as the loading frequency and maximum fatigue stress were increased. The implications of this temperature rise on fatigue life are discussed in a later section.

\footnotetext{
${ }^{++}$For uniaxial fatigue loading, the strain range $\Delta \varepsilon$ is related to the nominal stress range $\Delta \sigma$ and the axial modulus $E_{\mathrm{c}}$ by $\Delta \varepsilon=\Delta \sigma / E_{\mathrm{c}}$.
} 


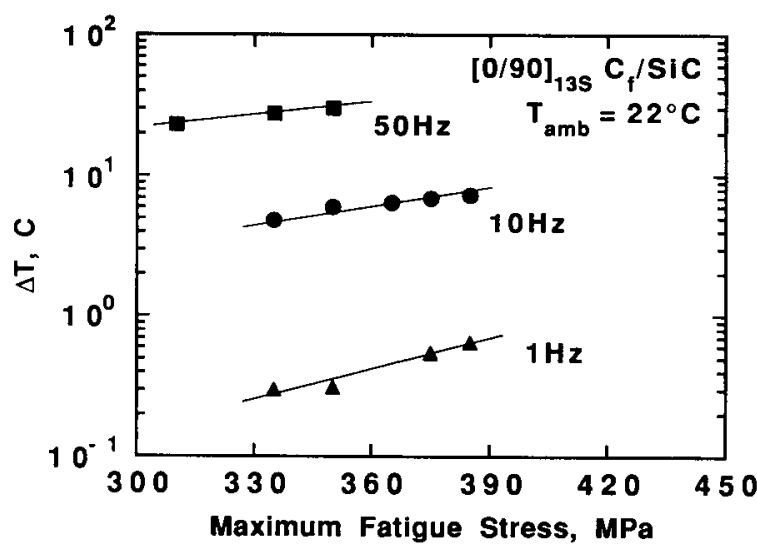

Fig. 13. Stress and loading frequency dependence of maximum temperature rise for the tension-tension fatigue of $\mathrm{C}_{\mathrm{f}} / \mathrm{SiC}$ specimens. In many instances the short duration of the $50-\mathrm{Hz}$ experiments did not allow a determination of maximum temperature rise to be made. The ambient temperature was $22^{\circ} \mathrm{C}$.

\section{(7) Influence of Fatigue Loading on Monotonic Tensile Behavior}

The postfatigue monotonic tensile behavior of specimens that were fatigued to runout at $335 \mathrm{MPa}$ was investigated (only the specimens fatigued at 1 and $10 \mathrm{~Hz}$ survived at this stress level). As shown in Fig. 14, the stress-strain behavior and ultimate strength found after fatigue loading differed significantly from that found for virgin specimens. Moreover, for stresses above roughly $200 \mathrm{MPa}$, the tangent modulus was higher than that found for virgin specimens.

To determine if the increase in strength observed after fatigue could be attributed specifically to the cyclic loading process, a specimen was subjected to sustained static loading for $28 \mathrm{~h}$ at a stress of $335 \mathrm{MPa}\left(28 \mathrm{~h}\right.$ is the time equivalent to $1 \times 10^{6}$ fatigue cycles at $10 \mathrm{~Hz}$ ). As shown in Fig. 14, the residual strength after static loading was approximately the same as that found with virgin specimens (a similar result was obtained for a specimen that was statically loaded for $28 \mathrm{~h}$ at $375 \mathrm{MPa}$ ). The residual strain offset (see Fig. 14) and average matrix crack spacing were similar for the static and cyclic loading histories. Moreover, the tensile modulus measured after fatigue and static loading was virtually identical up to the failure stress of approximately $420 \mathrm{MPa}$. The similarity in residual strain, matrix crack spacing, and modulus for the fatigued and statically loaded specimens leads to an important question; namely, what is the difference between the local microstructural damage states for static and cyclic loading that provides the strength increase after cyclic loading? Since the answer to this question will provide insight into the microstructural changes that occur during fatigue loading, it is of interest to speculate on possible mechanisms. Cyclic loading would tend to relieve the stress concentration near fiber kinks by a process of matrix fracture and interfacial debonding, followed by cyclic wear along fiber/ matrix and fiber/fiber interfaces (note that although the surface crack spacings were similar for static and cyclic loading, cyclic loading may be required for the propagation of cracks into the specimen interior). Support for this mechanism was obtained from microstructural investigation of the specimens that failed under fatigue loading; these specimens typically showed a random distribution of $0^{\circ}$ fiber failures within the fiber cloth, whereas virgin specimens, loaded monotonically to failure, failed predominantly by bundle rupture near the crossover points of the $0^{\circ}$ and $90^{\circ}$ fiber bundles, indicating that stress concentration at these locations limits the strength.

\section{(8) Fatigue Life-Discussion}

The reduction in fatigue life observed at $50 \mathrm{~Hz}$ is in general agreement with recent experimental results that the tensiontension fatigue life of unidirectional Nicalon/CAS-II composites decreased by several orders of magnitude as the loading frequency was increased from 10 to $350 \mathrm{~Hz} .{ }^{11}$ Although it appears

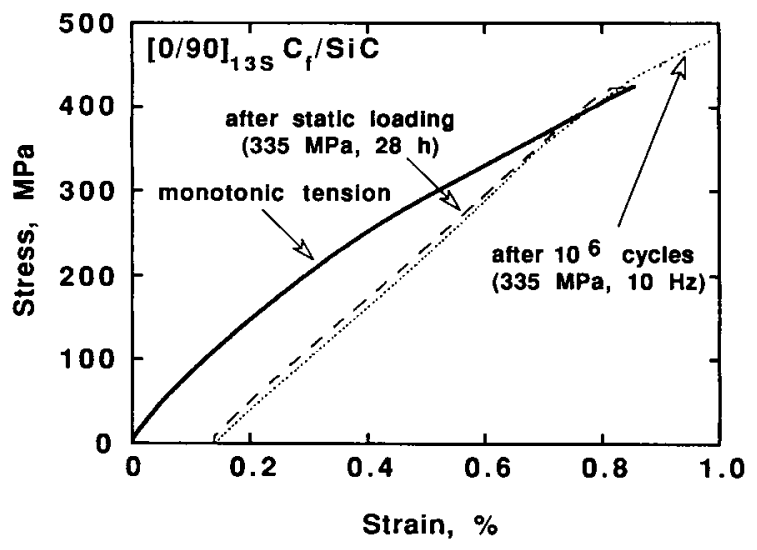

Fig. 14. Comparison between the initial monotonic tensile behavior of $\mathrm{C}_{\mathrm{f}} / \mathrm{SiC}$ composites and the tensile behavior after fatigue or static loading. The fatigue experiment was conducted for $1 \times 10^{6}$ cycles at a peak stress of $335 \mathrm{MPa}(R=0.1)$ and loading frequency of $10 \mathrm{~Hz}$. The static loading experiment was conducted at a nominal stress of 335 MPa for a period of $28 \mathrm{~h}\left(28 \mathrm{~h}\right.$ corresponds to $1 \times 10^{6}$ cycles at $10 \mathrm{~Hz}$ ). Note that the strength after static loading was limited to the monotonic strength found for virgin specimens.

that most fiber-reinforced ceramics experience a decrease in fatigue life when subjected to high loading frequencies, the mechanisms responsible for this decrease may differ depending upon the particular composite system. In other words, there may be several mechanisms acting in parallel-the dominance of a particular mechanism depending upon the fiber architecture and frictional heating characteristics. For example, in the case of unidirectional Nicalon/CAS composites, the frequency dependence of fatigue life is caused by accelerated microstructural damage that occurs in the vicinity of the fiber/matrix interface at high loading frequencies (in this composite differential thermal expansion associated with the near-interface temperature rise increased the amount of radial cracking in the matrix). ${ }^{11}$ For the $\mathrm{C}_{\mathrm{f}} / \mathrm{SiC}$ composites, there was a definite change in failure mode at $50 \mathrm{~Hz}$; compared to fatigue failures at 1 and $10 \mathrm{~Hz}$, failures at $50 \mathrm{~Hz}$ exhibited considerably more delamination between the fiber plies. Because of the relatively low temperature rise found with $\mathrm{C}_{\mathrm{f}} / \mathrm{SiC}$ composites (at $50 \mathrm{~Hz}$ the bulk temperature rise was $27^{\circ} \mathrm{C}$ for a peak stress of 335 $\mathrm{MPa}$ ), it is plausible to assume that interfacial temperature did not play an important role in the fatigue damage process (e.g., by the generation of differential thermal strains which could further propagate debonding or matrix fracture). This leads us to speculate on other possible damage mechanisms that would dominate in woven composites such as $\mathrm{C}_{\mathrm{f}} / \mathrm{SiC}$. For example, it is possible that at $50 \mathrm{~Hz}$ a different microstructural damage state evolves during the initial stages of fatigue. This hypothesis is supported by recent room-temperature fatigue experiments with $0^{\circ} / 90^{\circ} \mathrm{CVI}$ Nicalon $\mathrm{SiC}_{\mathrm{f}} / \mathrm{SiC}$ composites which show that prefatigue at low stress levels and loading frequencies can significantly increase the fatigue limit at higher loading frequencies. ${ }^{26}$ It can be inferred from these results that it takes a finite amount of time to develop a favorable microstructural "damage state." High frequency fatigue loading may not allow sufficient time for a redistribution in internal stresses to occur during the initial stages of fatigue in brittle-matrix composites with woven fiber architectures. In the case of $\mathrm{C}_{\mathrm{f}} / \mathrm{SiC}$ composites this favorable damage state presumably lowers the residual stresses in the composite and decreases the stress intensity near matrix cracks. The possibility also exists that the degree of interfacial wear increases with loading frequency. This would lead to further crack extension as the crack bridging force decreases. At this stage of the research we cannot be more specific about the precise damage mechanisms. It is clear that additional work is required to further elucidate the mechanisms of high-frequency fatigue damage in $\mathrm{C}_{\mathrm{f}} / \mathrm{SiC}$ composites. This effort must include 
an analysis of the stress distribution near the bridging fiber bundles and the failure probability of the segments of the fiber bundles that bridge the many matrix cracks present in $\mathrm{C}_{\mathrm{f}} / \mathrm{SiC}$ composites.

\section{(9) Summary Remarks}

Although one of the primary objectives of this paper was met, namely to determine if loading frequency influences the fatigue life of $\mathrm{C}_{\mathrm{f}} / \mathrm{SiC}$ composites, many issues remain concerning the mechanisms that are responsible for the reduction in fatigue life. In particular, experiments need to be conducted at much higher loading frequencies to determine if the fatigue life degrades further at loading frequencies above $50 \mathrm{~Hz}$ (as has been recently observed with unidirectional Nicalon/CAS-II composites). ${ }^{11}$ This frequency dependence of fatigue life has many practical implications, since fiber-reinforced ceramics are under consideration for use as structural members in advanced aircraft and gas turbines. These applications will involve lowamplitude high-frequency fatigue loading at both ambient and elevated temperatures. At elevated temperatures it is also important to determine how creep-fatigue interactions will influence component life and residual strength.

\section{Conclusions}

(1) The fatigue limit of $0^{\circ} / 90^{\circ} C_{f} /$ SiC composites decreases as the loading frequency is increased. Compared to the fatigue life at 1 and $10 \mathrm{~Hz}$, the fatigue life was lower at $50 \mathrm{~Hz}$. For loading frequencies of 1 and $10 \mathrm{~Hz}$ the fatigue limit was $335 \mathrm{MPa}$, which is $80 \%$ of the initial monotonic strength of approximately $420 \mathrm{MPa}$. At $50 \mathrm{~Hz}$ the fatigue limit was below $310 \mathrm{MPa}$.

(2) After an initial decay, a slight recovery in cyclic stressstrain modulus was observed during fatigue at $335 \mathrm{MPa}$ under frequencies of 1 and $10 \mathrm{~Hz}$; a progressive reduction in composite stiffness was found during fatigue above $335 \mathrm{MPa}$. At the fatigue limit ( $335 \mathrm{MPa}$ ), the modulus recovered by as much as $10 \%$ compared to the first-cycle modulus). Above the fatigue limit, the rate of modulus decay increased substantially with a small increase in stress.

(3) For fatigue at a maximum stress of $335 \mathrm{MPa}$, and for loading frequencies of 1 and $10 \mathrm{~Hz}$, the matrix crack spacing decreased rapidly within the first 100 cycles and remained constant thereafter. The decrease in matrix crack spacing occurred at a higher rate than the decay in modulus, indicating that other factors contributed to the decay in modulus; probable mechanisms include a decrease in frictional shear stress along the fiber/matrix interface, internal crack growth and fiber fractures. For specimens fatigued above the fatigue limit, the crack spacing exhibited a continual decrease from the onset of loading.

(4) Internal frictional heating was observed at all frequencies and stress levels studied. The extent of frictional heating increased with an increase in maximum fatigue stress and loading frequency. During long-duration fatigue, an initial temperature rise, followed by a gradual decrease was observed. In parallel with the decrease in temperature, a gradual decrease in stress-strain hysteresis was observed; these results support a process of gradual wear of the fiber/fiber and fiber/matrix interfaces.

(5) The tensile strength of the composite increased after low-frequency fatigue at a maximum stress of $335 \mathrm{MPa}$. After $1 \times 10^{\circ}$ fatigue cycles at $335 \mathrm{MPa}$, the ultimate strength was $500 \mathrm{MPa}$, compared to approximately $420 \mathrm{MPa}$ for virgin specimens. Specimens subjected to static loading at 335 and 375 MPa for $28 \mathrm{~h}$ exhibited a residual strength similar to that found with virgin specimens. It was proposed that the strength increase is related to a decrease in the stress concentration near the crossover points between the $0^{\circ}$ and $90^{\circ}$ fibers.

(6) Insight into the mechanisms of fatigue damage in brittle-matrix composites with woven fiber architectures was obtained. Fatigue damage is intimately related to the nonuniform stress and strain distributions present in woven fiber architectures. The nonuniformity of stress near the crossover points of fiber bundles leads to matrix cracking at these locations as the $0^{\circ}$ bundles attempt to align with the tensile loading direction. In parallel, delamination between individual plies occurs by cracking. Cyclic wear damage between the various fiber/ matrix and fiber/fiber interfaces in the composite accelerates the interfacial debonding process and leads to a redistribution in internal stresses.

\section{References}

'E. Minford and K. M. Prewo, "Fatigue of Silicon Carbide Reinforced Lithium Aluminosilicate Glass-Ceramics"; pp. 561-70 in Tailoring Multiphase and Composite Ceramics. Edited by C. G. Patano and R. E. Messing. Plenum Publishing Corp., New York, 1986.

${ }^{2}$ K. M. Prewo, "Fatigue and Stress Rupture of Silicon Carbide Fibre-Reinforced Glass Ceramics," J. Mater. Sci., 22, 2695-701 (1987).

${ }^{3}$ E. Y. Luh, R. H. Dauskardt, and R. O. Ritchie, "Cyclic Fatigue-Crack Growth Behavior of Short Cracks in SiC-Reinforced LAS Glass-Ceramic Composite," J. Mater. Sci. Lett., in press.

${ }^{4} \mathrm{C}$. Q. Rousseau, "Monotonic and Cyclic Behavior of a Silicon Carbide/Calcium Aluminosilicate Ceramic Composite"; in Thermal and Mechanical Behavior of Metal Matrix and Ceramic Matrix Composites, ASTM STP 1080 . Edited by J. M. Kennedy, H. H. Moeller, and W. S. Johnson. American Society for Testing and Materials, Philadelphia, PA, 1990.

${ }^{5}$ L. P. Zawada, L. M. Butkus, and G. A. Hartman, "Room Temperature Tensile and Fatigue Properties of SiC Fiber-Reinforced Aluminosilicate Glass"; presented at the 14th Annual Conference on Ceramics and Advanced Materials, Cocoa Beach, FL, January 14-17, 1990.

${ }^{6}$ L. Butkus and L. P. Zawada, "Room Temperature Tensile and Fatigue Properties of Silicon Carbide Fiber-Reinforced Ceramic Matrix Composites"; presented at Aeromat '90, Long Beach, CA, May 21-24, 1990.

'J. W. Holmes and C. Cho, "Experimental Observations of Frictional Heating in a Fiber Reinforced Ceramic,"J. Am. Ceram. Soc., 75 [4] 929-38 (1992).

${ }^{8}$ K. M. Prewo, B. Johnson, and S. Starrett, "Silicon Carbide Fiber-Reinforced Glass Ceramic Composite Tensile Behavior at Elevated Temperature," J. Mater. Sci., 24, 1373-79 (1989).

${ }^{9}$ J. W. Holmes, T. Kotil, and W. T. Foulds, "High Temperature Fatigue of SiC Fiber Reinforced $\mathrm{Si}_{3} \mathrm{~N}_{4}$ Ceramic Composites"; pp. 176-82 in Symposium on High Temperature Composites. Technomic Publishing Co., Lancaster, PA, 1989.

${ }^{10} \mathrm{~J}$. W. Holmes, "Influence of Stress-Ratio on the Elevated Temperature Fatigue of a SiC Fiber-Reinforced $\mathrm{Si}_{3} \mathrm{~N}_{4}$ Composite," J. Am. Ceram. Soc., 74 [7] $1639-45$ (1991).

"J. W. Holmes, X. Wu, and V. Ramakrishnan, "High-Frequency Fatigue of Fiber-Reinforced Ceramics"; presented at the 16th Annual Conference and Exposition on Ceramics and Advanced Composites, Cocoa Beach, FL, January 1992.

${ }^{12}$ C. Cho, J. W. Holmes, and J. R. Barber, "Estimation of Interfacial Shear in Ceramic Composites from Frictional Heating Measurements," J. Am. Ceram. Soc., 74 [11] 2802-808 (1991).

${ }^{13}$ J. W. Holmes and S. F. Shuler, "Temperature Rise During Fatigue of FibreReinforced Ceramics," J. Mater. Sci. Lett., 9, 1290-91 (1990).

${ }^{14}$ M. Gomina, F. Abbe, P. Fourvel, M.-H. Rouillon, J. Vicens, and J.-L. Chermant, "Mechanical Behavior and Microstructure of Ceramic Matrix Composites with Long Ceramic Fibers," Lattice Defects Ceram., 75-86 (1989).

${ }^{15} \mathrm{~L}$. Heraud and P. Spriet, "High Toughness C-SiC and SiC-SiC Composites in Heat Engines"; pp. 217-24 in Whisker and Fiber Toughened Ceramics. Edited by R. A. Bradley, D. E. Clark, D. C. Larsen, and J. O. Stiegler. ASM International, Metals Park, OH, 1988.

${ }^{16} \mathrm{~J}$. W. Holmes, "A Technique for Elevated Temperature Creep and Tensile Fatigue Testing of Fiber-Reinforced Ceramics," J. Compos. Mater., 26 [6] 91532 (1992).

${ }^{17}$ C. Cho, J. W. Holmes, and J. R. Barber, "Distribution of Matrix Cracks in a Uniaxial Composite," J. Am. Ceram. Soc., 75 [2] 316-24 (1992).

${ }^{18} \mathrm{~J}$. W. Holmes and S. F. Shuler, Research Memorandum No. 102, September 1989, "Influence of Loading Rate on the Monotonic Tensile Behavior of Fiber Reinforced Ceramics." Available through Ceramic Composites Research Laboratory, Department of Mechanical Engineering and Applied Mechanics, 1065 GGBL, University of Michigan, Ann Arbor, MI 48109-2125.

${ }^{19}$ J. Pernot and L. P. Zawada, "Tensile Behavior of Continuous Fiber Ceramic Matrix Composites"; presented at the 16th Annual Conference on Ceramics and Advanced Materials, Cocoa Beach, FL, January 14-17, 1990.

${ }^{20}$ R. Carter, E. I. du Pont de Nemours Co.; unpublished research, February 1990.

${ }^{21}$ R. H. Dauskardt, D. B. Marshall, and R. O. Ritchie, "Cyclic Fatigue Crack Propagation in Mg-PSZ Ceramics," J. Am. Ceram. Soc., 73 [4] 893-903 (1990). ${ }^{22}$ M. J. Reece, F. Guiu, and M. F. R. Sammur, "Cyclic Fatigue Crack Propagation in Alumina under Direct Tension-Compression Loading," J. Am. Ceram. Soc., 72 [2] 348-52 (1989).

${ }^{23}$ J. T. Beals and I. Bar-On, "Fracture Toughness and Fatigue Crack Propagation of Silicon Nitride with Two Different Microstructures," Ceram. Eng. Sci. Proc., 11 [7-8] 1061-71 (1990).

${ }^{24}$ A. G. Evans, "Fatigue in Ceramics," Int. J. Fract., 16 [10] 485-98 (1980).

${ }^{25}$ A. G. Evans and M. Linzer, "High Frequency Cyclic Crack Propagation in Ceramic Materials," Int. J. Fract., 12 [2] 217-22 (1976).

${ }^{26} \mathrm{X}$. Wu and J. W. Holmes, "Influence of Fatigue Loading History on the Residual Strength of 2-D SiC/SiC Ceramic Composites"; unpublished work. $\square$ 